\title{
Minisequencing mitochondrial DNA pathogenic mutations
} Vanesa Álvarez-Iglesias ${ }^{1,2}$, Francisco Barros ${ }^{2}$, Ángel Carracedo ${ }^{1,2}$ and Antonio Salas*1

\begin{abstract}
Address: ${ }^{1}$ Unidade de Xenética, Instituto de Medicina Legal, Facultad de Medicina, Universidad de Santiago de Compostela, Galicia, Spain and ${ }^{2}$ Fundación Pública Galega de Medicina Xenómica (FPGMX), Hospital Clínico Universitario, Universidad de Santiago de Compostela, Galicia, Spain
\end{abstract}

Email: Vanesa Álvarez-Iglesias - vaneiml@usc.es; Francisco Barros - apimlbar@usc.es; Ángel Carracedo - apimlang@usc.es; Antonio Salas* - apimlase@usc.es

* Corresponding author

Published: 10 April 2008

BMC Medical Genetics 2008, 9:26 doi:10.1 186/147/-2350-9-26

This article is available from: http://www.biomedcentral.com/I47I-2350/9/26

(C) 2008 Álvarez-Iglesias et al; licensee BioMed Central Ltd.

This is an Open Access article distributed under the terms of the Creative Commons Attribution License (http://creativecommons.org/licenses/by/2.0), which permits unrestricted use, distribution, and reproduction in any medium, provided the original work is properly cited.
Received: 26 September 2007

Accepted: 10 April 2008

\begin{abstract}
Background: There are a number of well-known mutations responsible of common mitochondrial DNA (mtDNA) diseases. In order to overcome technical problems related to the analysis of complete mtDNA genomes, a variety of different techniques have been proposed that allow the screening of coding region pathogenic mutations.
\end{abstract}

Methods: We here propose a minisequencing assay for the analysis of mtDNA mutations. In a single reaction, we interrogate a total of 25 pathogenic mutations distributed all around the whole mtDNA genome in a sample of patients suspected for mtDNA disease.

Results: We have detected II causal homoplasmic mutations in patients suspected for Leber disease, which were further confirmed by standard automatic sequencing. Mutations m. I I 778G $>$ A and $\mathrm{m}$. | 4484T>C occur at higher frequency than expected by change in the Galician (northwest Spain) patients carrying haplogroup J lineages (Fisher's Exact test, $P$-value $<0.01$ ). The assay performs well in mixture experiments of wild:mutant DNAs that emulate heteroplasmic conditions in mtDNA diseases.

Conclusion: We here developed a minisequencing genotyping method for the screening of the most common pathogenic mtDNA mutations which is simple, fast, and low-cost. The technique is robust and reproducible and can easily be implemented in standard clinical laboratories.

\section{Background}

There are over 100 point mutations putatively associated with human mtDNA diseases [1]; however, only a small percentage of these mutations were properly confirmed http://www.mitomap.org/rimtab2.html. In fact, the pathogenicity of some mutations is still under question due to the fact that the conclusions claimed in a substantial number of studies do not rest on solid grounds or are partially or completely flawed [2-5].
During this last two decades, many different techniques were designed for the screening of mtDNA pathogenic mutations, including restriction fragment length polymorphism (RFLP) analysis, heteroduplex analysis (HDA), single strand conformation polymorphisms (SSCP), etc [6-11]. The main disadvantage of these classical screening methods is that, due to the intrinsic nature of the techniques, many mutations usually pass unnoticed. Novel and more efficient strategies have recently been proposed 
that allow the screening of entire mtDNA genomes; for instance, the mismatch-specific DNA endonuclease "Surveyor $^{\mathrm{TM}}$ Nuclease" seems to be particularly useful when the most common pathogenic mutations have been ruled out previously (e.g. [12]). Ideally, the gold standard of sequencing the whole genome would solve the problem; nevertheless, this strategy is labor-intensive and therefore unfeasible for routine molecular diagnosis (taking into account the capacities of standard laboratories). Screening methods are also difficult to standardize and some of them are not suitable for replication assays due to their dependence on for instance electrophoretic conditions.

Minisequencing techniques have demonstrated to be efficient in other fields of research, such as forensic and population genetics [13-18], but also in clinical research [19]. This approach, also known as single nucleotide primer extension, allows the determination of the polymorphic position by DNA polymerase addition of the ddNTP complementary to the base interrogated. The primer anneals therefore to its target DNA immediately adjacent to the SNP under scrutiny. Here we present a minisequencing multiplex design which is a rapid, sensitive and low cost assay for screening mtDNA pathogenic mutations in patients suffering mtDNA disease.

\section{Methods}

\section{Subject and SNP selection}

Blood sample of 15 patients was sent to the Fundación Pública Galega de Medicina Xenómica located in the Hospital Clínico of Santiago de Compostela (Galicia, Spain). Six of these patients are from Galicia (northwest Spain; [20]), and three other patients are from southeast Spain (in the Mediterranean coast); the regional Spanish provenance of the other two patients is unknown. Four of these patients presented clinical features of an undetermined neuropathy, while the rest of the patients were analyzed under suspicion of Leber disease. Written informed consent was obtained from all patients and the study was approved by the institutional review board of the University of Santiago de Compostela (Spain). All the samples were genotyped for a set of 25 variants, 21 are confirmed pathogenic mutations related to different mtDNA diseases such as MELAS, LHON, Leigh Disease, and NARP. These mutations are distributed all around the mtDNA molecule and 'hit' different mtDNA genes (Table 1). All the selected mutations, with the only exception of

Table I: Characteristics of the mutations incorporated in our multiplex design

\begin{tabular}{|c|c|c|c|c|}
\hline POSITIONS & Base change & Amino Acid change & Locus & Disease $^{l}$ \\
\hline 3243 & $A>G$ & tRNA Leu (UUR) & MT-TLI & MELAS, DM/DMDT, CPEO, MM \\
\hline 3460 & $G>A$ & $\mathrm{Ala}>\mathrm{Thr}$ & MT-NDI & LHON \\
\hline 3697 & $G>A$ & Gly>Arg & MT-NDI & MELAS \\
\hline 3946 & $G>A$ & Glu>Lys & MT-NDI & MELAS \\
\hline 3949 & $\mathrm{~T}>\mathrm{C}$ & Tyr $>$ Lys & MT-NDI & MELAS \\
\hline 7445 & $A>G$ & Ter $>$ Ter & MT-COI & SNHL \\
\hline 7445 & $A>C$ & Ter $>$ Ser & MT-COI & DEAF \\
\hline 8993 & $\mathrm{~T}>\mathrm{G}$ & Leu>Arg & MT-ATP6 & NARP \\
\hline 8993 & $\mathrm{~T}>\mathrm{C}$ & Leu>Pro & MT-ATP6 & NARP, Leigh Disease \\
\hline 9176 & $\mathrm{~T}>\mathrm{C}$ & Leu>Pro & MT-ATP6 & FBSN, Leigh Disease \\
\hline 9176 & $\mathrm{~T}>\mathrm{G}$ & Leu>Arg & MT-ATP6 & Leigh Disease \\
\hline 10158 & $\mathrm{~T}>\mathrm{C}$ & Arg > Pro & MT-ND3 & Leigh Disease \\
\hline 10191 & $\mathrm{~T}>\mathrm{C}$ & Arg $>$ Pro & MT-ND3 & ESOC, Leigh-like Disease \\
\hline 10663 & $\mathrm{~T}>\mathrm{C}$ & $\mathrm{Val}>\mathrm{Ala}$ & MT-ND4 & LHON \\
\hline 11777 & $C>A$ & Arg $>$ Ser & MT-ND4 & Leigh Disease \\
\hline 11778 & $G>A$ & $\mathrm{Arg}>\mathrm{His}$ & MT-ND4 & LHON \\
\hline 11832 & $G>A$ & Trp>Ter & MT-ND4 & Exercise Intolerance \\
\hline 12706 & $\mathrm{~T}>\mathrm{C}$ & Phe $>$ Leu & MT-ND5 & Leigh Disease \\
\hline 13513 & $G>A$ & Asp $>$ Asn & MT-ND5 & MELAS, Leigh Disease \\
\hline $135 \mid 4$ & $A>G$ & Asp>Gly & MT-ND5 & MELAS \\
\hline 14459 & $G>A$ & $\mathrm{Ala}>\mathrm{Val}$ & MT-ND6 & LYDT, Leigh Disease \\
\hline 14482 & $C>A$ & Met>lle & MT-ND6 & LHON \\
\hline 14482 & $C>G$ & Met>lle & MT-ND6 & LHON \\
\hline 14484 & $\mathrm{~T}>\mathrm{C}$ & Met $>$ Val & MT-ND6 & LHON \\
\hline 14487 & $\mathrm{~T}>\mathrm{C}$ & Met $>$ Val & MT-ND6 & Dystonia, Leigh Disease \\
\hline
\end{tabular}

\footnotetext{
' List of some diseases where these mutations are frequently observed: CPEO: Chronic Progressive External Ophthalmoplegia; DEAF Maternally inherited DEAFness or aminoglycoside-induced DEAFness DM: Diabetes Mellitus; LDYT: Leber's hereditary optic neuropathy and DysTonia; LHON: Leber Hereditary Optic Neuropathy; MELAS: Mitochondrial Encephalomyopathy, Lactic Acidosis, and Stroke-like episodes; MM: Mitochondrial Myopathy; NARP: Neurogenic muscle weakness, Ataxia, and Retinitis Pigmentosa; alternate phenotype at this locus is reported as Leigh Disease; SNHL: SensoriNeural Hearing Loss
} 
m.3243A>G, consist of non-synonymous substitutions (both transitions and transversion, but note that the minisequencing technique could be also suitable for interrogating indels [17]).

\section{Primer design}

The primers both for PCR amplification (Table 2) and minisequencing reaction (Table 3 ) were designed to have an annealing temperature around $60^{\circ} \mathrm{C}$ using Primer3 software http://frodo.wi.mit.edu/cgi-bin/primer3. The sequence databases at the National Centre for Biotechnology Information (NCBI; http://www.ncbi.nlm.nih.gov) were interrogated using the online BLAST tool to test the primers against possible repetitive sequences and sequence homologies in the autosomal genome. Each primer pair for PCR amplification and each single base extension primer were selected independently and AutoDimer http://www.cstl.nist.gov/biotech/strbase/Auto DimerHomepage/AutoDimerProgramHomepage.htm was used to test for potential hairpin structures and primer-dimer problems.

Although the simultaneous occurrence of more than one pathogenic mutation in a single individual is infrequent, it could be possible that the presence of m.14484T $>C$ could interfere with the genotyping of m.14487T>G (due to their physical proximity). Therefore, in order to avoid potential artifacts due to deficient annealing, we have designed a degenerate extension primer containing a mixture of nucleotide $\mathrm{C}$ and $\mathrm{T}$ at site 14484 . The same rationale applies to variation at other two positions. According to our design, m.14482C>G mutation could interfere with the genotyping at position 14484; and the presence of $\mathrm{m} .3946 \mathrm{G}>\mathrm{A}$ could alter the genotyping of m.3949T>C; we therefore designed another extension degenerate primer containing $\mathrm{C}$ and $\mathrm{G}$ at site 14482 and another additional extension degenerated primer carrying $\mathrm{G}$ and $\mathrm{A}$ at site 3946 (Table 3).

\section{PCR multiplex amplification}

The SNPs were PCR amplified in 13 amplicons with sizes ranging from 89 and $196 \mathrm{bp}$. The amplicons are deliberately designed to be small in order to facilitate the analysis of samples that are highly degraded or with low quantity of DNA. Some amplicons encompass several SNPs (Table 1). We performed multiplex reaction using $5 \mathrm{ng}$ of DNA template and PCR master mix of QIAGEN Kit Multiplex PCR (Qiagen, Hilden, Germany), amplification primers and their final concentrations are in Table 2. Amplification was carried out in a 9700 Thermocycler (Applied Biosystems, Foster City, CA, USA). After a $95^{\circ} \mathrm{C}$ preincubation step for 15 minutes, PCR was performed in a total of 30 cycles using the following conditions: $94^{\circ} \mathrm{C}$ denaturation for 30 seconds, annealing at $60^{\circ} \mathrm{C}$ for 90 seconds and extension at $72^{\circ} \mathrm{C}$ during 90 seconds, followed by a 15 minutes of final extension at $72^{\circ} \mathrm{C}$ and $4{ }^{\circ} \mathrm{C}$ until removed from thermocycler. PCR products were checked by polyacrylamide gel electrophoresis (T9, C5) visualized by silver staining.

\section{Minisequencing reaction}

Previous to minisequening reaction, PCR products are treated with ExoSAP-IT (Amershan Bioscences, Uppsala, Sweden) to remove excess primers and un-incorporated dNTPs: $3 \mu \mathrm{l}$ of PCR product was incubated with $1.5 \mu \mathrm{l}$ for 15 minutes at $37^{\circ} \mathrm{C}$ followed by 15 minutes at $80^{\circ} \mathrm{C}$ for enzyme inactivation. Minisequencing reaction is performed using $\mathrm{SNaPshot}^{\mathrm{TM}}$ Kit $(\mathrm{AB})$. We modified the length of the primers (between 25 and $76 \mathrm{bp}$ ) by the addition of non-homologous tails, poly(dGACT) added at the 5 '- end (Table 3 ). The minisequencing reaction was carried out in a total volume of $10 \mu \mathrm{l}$ comprising $3 \mu \mathrm{l}$ of the SNaPshot ${ }^{\mathrm{TM}}$ Kit (AB), $1.5 \mu$ l PCR product, $1.5 \mu$ l of extension primers mix (final concentrations are between 0.1 and $0.6 \mu \mathrm{M}$ ) (Table 3 ), and water up to $10 \mu \mathrm{l}$. The reaction was performed in a 9700 Thermocycler $(\mathrm{AB})$ following the recommendations of the manufacturer: 25 cycles of dena-

Table 2: Amplification primers

\begin{tabular}{|c|c|c|c|c|}
\hline POSITIONS & FORWARD & REVERSE & SIZE (bp) & Final Concentration $(\mu \mathrm{M})$ \\
\hline 3243 & tatacccacacccacccaag & ggccatgggtatgttgttaag & 118 & 0.2 \\
\hline 3460 & ccgaacgaaaaattctaggc & gcggtgatgtagagggtgat & 153 & 0.2 \\
\hline 3697 & gcctagccgtttactcaatcc & tgagattgtttggggctactgc & 94 & 0.15 \\
\hline $3946 / 39491$ & tagcagagaccaaccgaacc & gaagattgtagtggtgagggtgt & 157 & 0.2 \\
\hline 7445 & ccctaccacacattcgaagaa & tggcttgaaaccagctttg & 89 & 0.2 \\
\hline 8993 & aatgccctagcccacttctt & aggtggcctgcagtaatgtt & 140 & 0.15 \\
\hline 9176 & aaatcgctgtcgccttaatc & tcattaggagggctgagagg & 154 & 0.3 \\
\hline $10158 / 10191$ & tcaacaccctcctagcctta & gggtaaaaggagggcaattt & 196 & 0.3 \\
\hline 10663 & acacccactccetcttagcc & ggccatatgtgttggagattg & 110 & 0.3 \\
\hline II777/II778/II832 & cacgggcttacatcctcatt & gggggtaaggcgaggttag & 157 & 0.2 \\
\hline 127061 & tgtagcattgttcgttacatgg & agttggaataggttgttagcgg & 146 & 0.2 \\
\hline $13513 / 13514$ & attggcagcctagcattagc & cagggaggtagcgatgagag & $|3|$ & 0.2 \\
\hline |4459/|4482/|4484/|4487 & ctccatcgctaaccccacta & ttctgaattttgggggaggt & 170 & 0.4 \\
\hline
\end{tabular}

IThese primers were reported in [16] 
Table 3: Minisequencing primers

\begin{tabular}{|c|c|c|c|c|c|}
\hline POSITIONS & Extension Primer ${ }^{I}$ & Length & Base change & Strand & Final Concentration $(\mu M)^{3}$ \\
\hline 10158 & acaactcaacggctacatagaaaaa & 25 & $\mathrm{~T}>\mathrm{C}$ & L & 0.2 \\
\hline 3946 & Cgaactagtctcaggcttcaacatc & 25 & $G>A$ & L & 0.2 \\
\hline 10663 & GACTGcaatattgtgcctattgccatactag & 31 & $T>C$ & L & 0.2 \\
\hline 3460 & $(\mathrm{GACT})_{2}$ Ggctactacaacccttcgctgac & 31 & $G>A$ & L & 0.2 \\
\hline 10191 & $(\mathrm{GACT})_{4}$ agtgcggcttcgaccctata & 36 & $\mathrm{~T}>\mathrm{C}$ & L & 0.3 \\
\hline 14459 & $(\mathrm{GACT})_{2}$ GACctcaggatactcctcaatagccatc & 36 & $G>A$ & L & 0.3 \\
\hline $14484^{2}$ & $(\mathrm{GACT})_{3}$ atcgctgtagtatatccaaagacaac $\mathrm{Ya}$ & 40 & $\mathrm{~T}>\mathrm{C}$ & L & 0.5 \\
\hline 3243 & $(\mathrm{GACT})_{4}$ GAacagggtttgttaagatggcag & 40 & $A>G$ & L & 0.2 \\
\hline 11777 & $(\mathrm{GACT})_{5}$ Gcaaactacgaacgcactcacagt & 44 & $C>A$ & L & 0.2 \\
\hline 7445 & $(\mathrm{GACT})_{5}$ tcgaagaacccgtatacataaaatctag & 48 & $A>G / C$ & L & 0.2 \\
\hline 12706 & $(\mathrm{GACT})_{9} g \mathrm{~g} g g$ taactaagattagtatggtaattagga & 52 & $\mathrm{~T}>\mathrm{C}$ & $\mathrm{H}$ & 0.2 \\
\hline 39492 & $(\mathrm{GACT})_{\|}$GAagtctcaggcttcaacatcRaa & 52 & $\mathrm{~T}>\mathrm{C}$ & L & 0.2 \\
\hline $14487^{2}$ & $(\mathrm{GACT})_{7}$ GctgtagtatatccaaagacaaccaSca & 56 & $\mathrm{~T}>\mathrm{C}$ & L & 0.6 \\
\hline 13513 & $(\mathrm{GACT})_{8} \mathrm{ttcctcacaggtttctactccaaa}$ & 56 & $G>A$ & L & 0.1 \\
\hline $135 \mid 4$ & $(\mathrm{GACT})_{10} T$ tgcggtttcgatgatgtgg & 60 & $A>G$ & $\mathrm{H}$ & 0.2 \\
\hline 3697 & $(\mathrm{GACT})_{9} \mathrm{CT}$ aaactcaaactacgccctgatc & 60 & $G>A$ & L & 0.2 \\
\hline 11778 & $(\mathrm{GACT}),{ }_{9}$ GAgaagtccttgagagaggattatgatg & 64 & $G>A$ & $\mathrm{H}$ & 0.3 \\
\hline 11832 & $(\mathrm{GACT})_{8}$ GACtcaaactctactcccactaatagcttttt & 64 & $G>A$ & L & 0.1 \\
\hline 9176 & $(\mathrm{GACT})$ । Gatccaagcctacgttttcacacttc & 70 & $T>C / G$ & L & 0.2 \\
\hline 14482 & $(\mathrm{GACT})_{\|}$gccatcgtcgctgtagtatatccaaagacaac & 73 & $C>A / G$ & L & 0.6 \\
\hline 8993 & $(\mathrm{GACT})_{13}$ Gcctactcattcaaccaatagccc & 76 & $T>G / C$ & L & 0.2 \\
\hline
\end{tabular}

I Capital letters indicate the segment of the primer belonging to the tail

2 These primers are 'degenerated' at the indicated position in the second column (see Material and Methods) using the IUB code

turation at $96^{\circ} \mathrm{C}$ for 10 seconds, annealing at $50^{\circ} \mathrm{C}$ for 5 seconds and extension at $60^{\circ} \mathrm{C}$ during 30 seconds. Unincorporated ddNTPs are eliminated with a treatment with SAP (Amershan Bioscences). The final volume (10 $\mu \mathrm{l})$ was treated with $1 \mu \mathrm{l}$ of SAP for 60 minutes at $37^{\circ} \mathrm{C}$ followed by 15 minutes at $80^{\circ} \mathrm{C}$ for enzyme inactivation.

The minisequencing products $(1.5 \mu \mathrm{l})$ were mixed with 10 $\mu \mathrm{l}$ of $\mathrm{HiDi}^{\mathrm{TM}}$ formamide (AB) and $0.25 \mu \mathrm{l}$ of GeneScan 120 LIZ (AB) and capillary electrophoresis was undertaken on an ABI PRISM $3130 \times$ l Genetic Analyzer (AB). The data was analyzed using GeneMapper ${ }^{\mathrm{TM}} 3.7$ Software (AB).

\section{Sequencing reaction}

All the 13 amplicons were sequenced in an ABI PRISM $3130 \times 1$ Genetic Analyzer $(\mathrm{AB})$ for all the patients with the aim of corroborating the mutations observed with the minisequencing assay. Technical details regarding sequencing reaction are given in [17].

\section{Results}

Only 13 amplicons are needed to interrogate the selected 25 variants. This is because (i) 'neighbouring' variants are genotyped using different minisequencing probes annealing at the same amplicon, and (ii) different minisequencing probes were designed to genotype different pathogenic substitutions occurring at the same mtDNA site. Therefore, for each of the sites 7445, 9176, and 14482, there are two common mtDNA mutations described in the literature as pathogenic, the most common one for each of these three sites was already confirmed (m.7445A $>\mathrm{G}, \mathrm{m} .9176 \mathrm{~T}>\mathrm{C}$, and m.14482C $>\mathrm{G})$, while the alternative one $(\mathrm{m} .7445 \mathrm{~A}>\mathrm{C}, \mathrm{m} .9176 \mathrm{~T}>\mathrm{G}$, and $\mathrm{m} .14482 \mathrm{C}>\mathrm{A}$ ) still bears the status of 'provisional' in MITOMAP. In addition, position 8993 has two already confirmed variants, namely, $\mathrm{T}$ to $\mathrm{C}$ and $\mathrm{T}$ to $\mathrm{G}$ substitutions.

We did not observe mutations in four patients presenting neurological symptoms. On the other hand, a pathogenic mutation was found for each of the other 11 patients with clinical suspicion of Leber disease (Table 4). All the mutations were confirmed by sequencing and were observed as homoplasmic using both minisequencing and automatic sequencing (Figure 1). Nine patients carried mutation m.11778G $>$ A whereas two patients carried m.14484T $>C$.

The two carriers of m.14484T>C lived in the same geographic (relatively isolated) village (namely, Burela) in the northern cost of Galicia $[20,21]$. These samples were submitted at different times to the laboratory and according to the carriers, their families were unrelated. Both patients share also the transition m.12696T>C (observed by sequencing), indicating that these individuals could actually share some recent common ancestor. The m.12696T $>C$ transition is not a frequent variant in Europe and likely constitutes a diagnostic variant of a minor HV1 sub-lineage (although this variant is also recurrent in at least other eight non-European haplogroups, including 


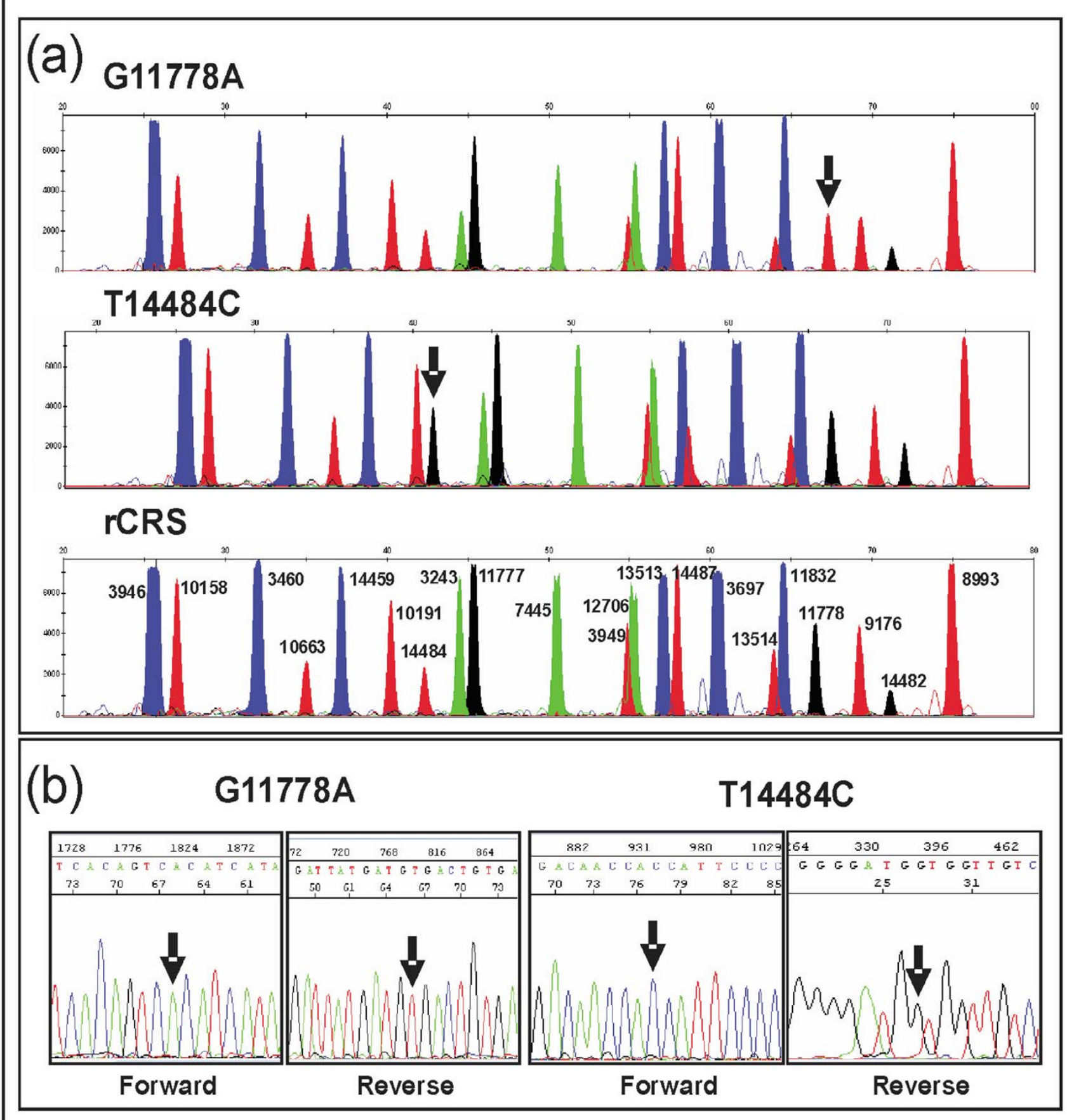

Figure I

Electropherograms showing (a) two different SNaPshot profiles carrying mutations m. I I778G>A and m. I4484T>C; rCRS [50] electropherogram is also shown indicating the whole set of mutations tested with the SNaPshot reaction; and (b) forward and reverse sequence electropherograms for these same mutations.

haplogroup J, see below): it appears in at least six haplogroup HV1 complete genomes (see for instance [22,23]). Therefore, the m.14484T $>\mathrm{C}$ transition could represent a founder pathogenic mutation responsible of Leber disease in Galicia (as it is the case of a wide spectrum of different non-mtDNA diseases [24,25]. 
Table 4: Patient samples analyzed in the present study

\begin{tabular}{|c|c|c|c|c|c|c|c|c|c|c|c|c|c|c|c|c|c|c|c|c|c|c|c|}
\hline & & 3 & 3 & 3 & 3 & 3 & 7 & 8 & 9 & I & I & I & I & I & I & I & $\mathbf{I}$ & $\mathbf{I}$ & I & I & $\mathbf{I}$ & I & \\
\hline & & 2 & 4 & 6 & 9 & 9 & 4 & 9 & I & 0 & 0 & 0 & I & I & I & 2 & 3 & 3 & 4 & 4 & 4 & 4 & \\
\hline & & 4 & 6 & 9 & 4 & 4 & 4 & 9 & 7 & I & I & 6 & 7 & 7 & 8 & 7 & 5 & 5 & 4 & 4 & 4 & 4 & \\
\hline & & 3 & 0 & 7 & 6 & 9 & 5 & 3 & 6 & 5 & 9 & 6 & 7 & 7 & 3 & 0 & I & I & 5 & 8 & 8 & 8 & \\
\hline & & & & & & & & & & 8 & I & 3 & 7 & 8 & 2 & 6 & 3 & 4 & 9 & 2 & 4 & 7 & Variants ${ }^{\prime}$ \\
\hline & rCRS & $\mathbf{A}$ & G & G & G & $\mathbf{T}$ & A & $\mathbf{T}$ & $\mathbf{T}$ & $\mathbf{T}$ & $\mathbf{T}$ & $\mathbf{T}$ & C & $\mathbf{G}$ & G & $\mathbf{T}$ & G & A & $\mathbf{G}$ & $\mathbf{T}$ & $\mathbf{T}$ & $\mathbf{T}$ & \\
\hline$\# 1$ & $|-|||$ & - & - & - & - & - & - & - & - & - & - & - & - & A & - & - & - & - & - & - & - & - & \\
\hline$\# 2$ & $D-112$ & - & - & - & - & - & - & - & - & - & - & - & - & A & - & - & - & - & - & - & - & - & 11812 \\
\hline$\# 3$ & $1-138$ & - & - & - & - & - & - & - & - & - & - & - & - & A & - & - & - & - & - & - & - & - & 10172 \\
\hline$\# 4$ & F-393 & - & - & - & - & - & - & - & - & - & - & - & - & A & - & - & - & - & - & - & - & - & \\
\hline$\# 5$ & C-436 & - & - & - & - & - & - & - & - & - & - & - & - & - & - & - & - & - & - & - & - & - & \\
\hline \#6 & B-703 & - & - & - & - & - & - & - & - & - & - & - & - & - & - & - & - & - & - & - & - & - & \\
\hline$\# 7$ & B-900 & - & - & - & - & - & - & - & - & - & - & - & - & A & - & - & - & - & - & - & - & - & \\
\hline$\# 8$ & B-90I & - & - & - & - & - & - & - & - & - & - & - & - & A & - & - & - & - & - & - & - & - & \\
\hline \#9 & D-992 & - & - & - & - & - & - & - & - & - & - & - & - & - & - & - & - & - & - & - & - & - & \\
\hline$\# 10$ & 1586 & - & - & - & - & - & - & - & - & - & - & - & - & A & - & - & - & - & - & - & - & - & \\
\hline \#II & 5699 & - & - & - & - & - & - & - & - & - & - & - & - & - & - & - & - & - & - & - & C & - & 12696 \\
\hline$\# 12$ & 5869 & - & - & - & - & - & - & - & - & - & - & - & - & - & - & - & - & - & - & - & C & - & 12696 \\
\hline$\# 13$ & G-495 & - & - & - & - & - & - & - & - & - & - & & - & A & - & - & - & - & - & - & - & - & \\
\hline$\# 14$ & 7218 & - & - & - & - & - & - & - & - & - & - & - & - & - & - & - & - & - & - & - & - & - & \\
\hline$\# 15$ & 9615 & - & - & - & - & - & - & - & - & - & - & - & - & A & - & - & - & - & - & - & - & - & $12705 \mathrm{C} / \mathrm{T}$ \\
\hline
\end{tabular}

I Variants detected by automatic sequencing (putatively unrelated to the disease outcome). Position I2705 is heteroplasmic C/T.

In order to further investigate this hypothesis, we additionally genotyped all the Galician samples for a set of haplogroup diagnostic mtDNA SNPs following [16] (Table 5). The two carriers of m.14484T $>C$ but also two other Galician samples carrying m.11778G>A could be allocated to haplogroup J (and not to HV1 as it could be inferred by the presence of m.12696T >C). Therefore, the observation of the m.14484T>C mutation in two unrelated patients from the above mentioned small Galician village could just reflect the already reported high incidence of Leber mutations within haplogroup J [26,27]. In fact, we also observe that the frequency of haplogroup $\mathrm{J}$ in healthy unrelated Galician individuals is $~ 14.7 \%$ $[20,21,28]$ but it occurs in four out of our six Galician patients ( $66.7 \%)$; the difference in prevalence is statistically significant (Fisher's Exact test, $P$-value $<0.006$ )

Other variants were also observed by sequencing analysis in $\mathrm{m} .11778 \mathrm{G}>\mathrm{A}$ carriers. For instance, the transition A11812G is diagnostic of haplogroup T2 and G10172A identifies haplogroup $\mathrm{J} 2 \mathrm{~b}$; these variants also appear sporadically in other haplogroup backgrounds. In addition, we observe a heteroplasmy at position 12705; transition C12705T is a well-known diagnostic site that (together with T16223C) leads from macro-haplogroup $\mathrm{N}$ to $\mathrm{R}$.

Mixtures of two different DNA bearing different SNP profiles were carried out in order to simulate mtDNA heteroplasmy, a common state in mtDNA disease patients. As

Table 5: Coding SNP and haplogroup status of the Galician patients

\begin{tabular}{|c|c|c|c|c|c|c|c|c|c|c|c|c|c|c|c|c|c|c|c|}
\hline & & & & & & & & & & & I & I & I & I & I & I & I & I & \\
\hline & & 3 & 3 & 4 & 4 & 4 & 4 & 4 & 6 & 7 & 0 & 0 & 0 & 0 & 2 & 2 & 3 & 4 & \\
\hline & & 9 & 9 & 2 & 5 & 5 & 7 & 7 & 7 & 0 & 3 & 4 & 4 & 8 & 3 & 7 & 9 & 7 & \\
\hline & & I & 9 & I & 2 & 8 & 6 & 9 & 7 & 2 & 9 & 0 & 6 & 7 & 0 & 0 & 6 & 6 & \\
\hline & & 5 & 2 & 6 & 9 & 0 & 9 & 3 & 6 & 8 & 8 & 0 & 3 & 3 & 8 & 5 & 6 & 6 & HG \\
\hline & rCRS & $\mathbf{G}$ & C & $\mathbf{T}$ & A & $\mathbf{G}$ & $\mathbf{A}$ & $\mathbf{A}$ & $\mathbf{T}$ & C & $\mathbf{A}$ & C & $\mathbf{T}$ & $\mathbf{T}$ & A & C & $\mathbf{A}$ & C & \\
\hline \#3 & $1-138$ & - & - & C & - & - & - & - & - & $\mathbf{T}$ & $\mathbf{G}$ & - & - & - & - & - & - & $\mathbf{T}$ & $\mathrm{J}$ \\
\hline$\# 4$ & F-393 & - & - & C & - & - & - & - & - & $\mathbf{T}$ & $\mathbf{G}$ & - & - & - & - & - & - & $\mathbf{T}$ & $\mathrm{J}$ \\
\hline$\# 10$ & 1586 & - & - & - & - & - & - & - & $\mathbf{G}$ & - & - & - & - & - & - & - & - & - & $\mathrm{H} 3$ \\
\hline$\# 11$ & 5699 & - & - & C & - & - & - & - & - & $\mathbf{T}$ & $\mathbf{G}$ & - & - & - & - & - & - & $\mathbf{T}$ & $J$ \\
\hline$\# 12$ & 5869 & - & - & C & - & - & - & - & - & $\mathbf{T}$ & $\mathbf{G}$ & - & - & - & - & - & - & $\mathbf{T}$ & $\mathrm{J}$ \\
\hline$\# 13$ & G-495 & - & - & - & - & - & - & - & - & $\mathbf{T}$ & - & - & - & - & G & - & - & $\mathbf{T}$ & $U$ \\
\hline
\end{tabular}

HG = haplogroup 
shown in Figure 2, the minisequencing assay is perfectly able to detect the mixtures at different proportions. According to [29] "the single most important disadvantage of the SNaPshot is that it seems less accurate than conventional PCR-RFLP analysis for [detecting] high levels of mutant mtDNA". Our results however indicate that the ability of SNaPshot for detecting heteroplasmy is actually equivalent to standard sequencing. Some fluorocromes 'project' more intensity in the electropherogram than other (as it also occurs with some sequencing chemistries), and this should be taking into account when quantifying the real proportions of wild:mutant DNA (heteroplasmy).

Although our primer design take into account the proximity of two pathologic mutations, it is not possible to consider all the potential polymorphisms that could hit within the annealing segments, and therefore alter the PCR efficacy (and in the worst of the cases, produce an artefact related to e.g. the spurious amplification of a NUMT; see below). This is however an universal problem affecting most of the genotyping techniques (including RFLP and sequencing) and therefore, the expert should be always alert under the possibility of false negative results. The experience of previous SNaPshot designs $[16,18,30]$ indicates however that the method is robust under the presence of polymorphisms.

Finally, the multiplex reaction was also tested in 102 control individuals. There were not false positives in this control sample and the SNP-minisequencing profiles were phylogenetically concordant $[31,32]$.

\section{Discussion}

MtDNA mutations are responsible for various clinical features, which often make diagnosis a considerable challenge. Since the mitochondria constitute the energetic 'factory' of all nucleated cells, mtDNA diseases affect many tissues with variable clinical outcomes. When searching the Mitomap database for pathogenic mtDNA mutations, many of them harbour the status of 'provisional', while some other stated as 'confirmed'; among the

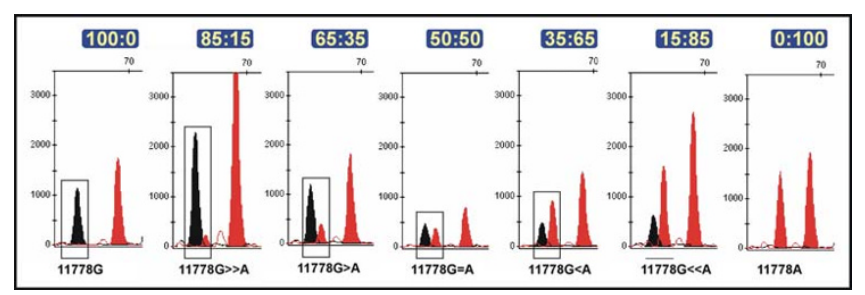

\section{Figure 2}

Partial electropherograms showing the performance of the $\mathrm{SNaPshot}$ assay with mixtures of wild:mutant DNAs. Numbers in the top indicate the percentages of wild:mutant mixture. later, some were recently questioned $[2,33,34]$. We here selected a total of 25 mutations, 21 of them were confirmed as pathogenic in common mtDNA diseases in multiple independent studies and considering different criteria, including the score system proposed by [33] (see also [35]) and also the complementary phylogenetic approach [2]. For instance, we included all the MTND gene mutations evaluated with the complex I pathogenicity scoring system of [33] (see their Table 2) and reaching the 16 top values $(\geq 30)$. Apart from the 21 confirmed mutations included in the design, the remaining four mutations were additionally included because they occur at lower frequencies at four of the initially 21 selected positions.

Among the selected mutations, we have the transition m.3243A $>\mathrm{G}$ which is a typical cause of MELAS [36] and MIDD [37]; transition m.8993T $>G$, responsible of a number of patients suffering NARP [38] and MILS [39]; transitions m.3460G $>\mathrm{A}, \mathrm{m} .11778 \mathrm{G}>\mathrm{A}, \mathrm{m} .14484 \mathrm{~T}>\mathrm{C}$, which are common causal mutations in LHON patients [40,41], etc. (see [42] for a review). It can be tentatively said that the selected SNPs actually cover an ample spectra of the fully confirmed causal mutations in the most common mtDNA diseases. For instance, according to [43], the prevalence of $m .3243 A>G$ is about 1 in 6,135 in the general (European) population; see also [44]. It is also worth to mention that it is straightforward to add mutations to our initial multiplex design because SNaPshot minisequencing is very flexible in this regard [17].

\section{Conclusion}

The minisequencing reaction presented here detected 11 mutations in an easy and straightforward manner in 11 different patients with clinical suspicion of Leber disease. All the mutations and their homoplasmic status were finally confirmed by automatic sequencing. We did not observed false positives in a substantial number of controls. We also simulated heteroplasmic states by mixing wild:mutant DNAs; the minisequencing technique demonstrates a good performance in detecting at least mixtures up to $1: 10$.

The multiplex reaction shows various advantages in the clinical field with respect to other techniques (see [17] for more details). For instance, the primers were designed in order to obtain amplicons of size ranging 89-196, a feature of special interest in a clinical context where often the laboratories have to deal with suboptimum samples containing low amounts of DNA or highly degraded DNA (paraphine imbibed samples, biopsies, etc.) as it is also the case with forensic samples [13]. Finally, we estimate that the cost of genotyping 25 SNPs is at least 20 times lower than the cost of RFLP genotyping (considering genotyping of one mutation at the time), and it can be done 
in less than three hours (including post-PCR purification, minisequencing reaction, purification of minisequencing products, electrophoresis, and documentation) for as many samples as the number of capillaries of the automatic sequencer.

Also important is the fact that minisequencing is robust respect potential artefacts related to false positives at NUMTs (author's unpublished data). Multiplex genotyping also prevents from artificial recombination; the later is a kind of common artefact that more easily arise as more independent fragments are genotyped for the same sample $[31,32,45-49]$.

Finally, the screening method presented here should not be considered as a substitute of complete genome sequencing. The latter should be performed when the minisequencing screening (or the use of other alternative strategies) fails to identify the causal mutation.

\section{Competing interests}

The author(s) declare that they have no competing interests.

\section{Authors' contributions}

VAI, FB, AC, and AS designed the study, collected and analyzed the data, and wrote the paper.

\section{Availability and requirements}

There are over 100 point mutations putatively associated with human mtDNA diseases [1]; however, only a small percentage of these mutations were properly confirmed http://www.mitomap.org/rimtab2.html. The primers both for PCR amplification (Table 2) and minisequencing reaction (Table 3 ) were designed to have an annealing temperature around $60^{\circ} \mathrm{C}$ using Primer3 software http:// frodo.wi.mit.edu/cgi-bin/primer3. The sequence databases at the National Centre for Biotechnology Information (NCBI; http://www.ncbi.nlm.nih.gov) were interrogated using the online BLAST tool to test the primers against possible repetitive sequences and sequence homologies in the autosomal genome. Each primer pair for PCR amplification and each single base extension primer were selected independently and AutoDimer http/ www.cstl.nist.gov/biotech/strbase/AutoDimer Homepage/AutoDimerProgramHomepage.htm was used to test for potential hairpin structures and primer-dimer problems.

\section{Acknowledgements}

The 'Ramón y Cajal' Spanish programme from the Ministerio de Educación y Ciencia (RYC2005-3), the grant from the Xunta de Galicia (PGIDIT06PXIB208079PR), and a grant from the Fundación de Investigación Médica Mutua Madrileña awarded to AS supported this project.

\section{References}

I. Schapira AH: Mitochondrial disease. Lancet 2006, 368(9529): $70-82$.

2. Bandelt HJ, Yao YG, Salas A, Kivisild T, Bravi CM: High penetrance of sequencing errors and interpretative shortcomings in mtDNA sequence analysis of LHON patients. Biochem Biophys Res Commun 2007, 352:283-291.

3. Yao YG, Salas A, Bravi CM, Bandelt HJ: A reappraisal of complete mtDNA variation in East Asian families with hearing impairment. Hum Genet 2006, I I 9(5):505-5 I5.

4. Bandelt HJ, Yao YG, Salas A: The search of 'novel' mtDNA mutations in hypertrophic cardiomyopathy: MITOMAPping as a risk factor. Int J Cardiol 2007 in press.

5. Kong QP, Bandelt HJ, Sun C, Yao YG, Salas A, Achilli A, Wang CY, Zhong L, Zhu CL, Wu SF, Torroni A, Zhang YP: Updating the East Asian mtDNA phylogeny: a prerequisite for the identification of pathogenic mutations. Hum Mol Genet 2006, I5(13):2076-2086.

6. Wallace DC, Brown MD, Lott MT: Mitochondrial DNA variation in human evolution and disease. Gene 1999, 238(1):21 I-230.

7. Barros F, Lareu MV, Salas A, Carracedo A: Rapid and enhanced detection of mitochondrial DNA variation using singlestrand conformation analysis of superposed restriction enzyme fragments from polymerase chain reaction-amplified products. Electrophoresis 1997, I 8(I):52-54.

8. Salas A, Rasmussen EM, Lareu MV, Morling N, Carracedo A: Fluorescent SSCP of overlapping fragments (FSSCP-OF): a highly sensitive method for the screening of mitochondrial DNA variation. Forensic Sci Int 200I, I 24(2-3):97-103.

9. Zeviani M, Gellera C, Antozzi C, Rimoldi M, Morandi L, Villani F, Tiranti V, DiDonato S: Maternally inherited myopathy and cardiomyopathy: association with mutation in mitochondrial DNA tRNA(Leu)(UUR). Lancet I99I, 338(8760): |43-147.

10. DiMauro S: Mitochondrial DNA medicine. Biosci Rep 2007, 27(I3):5-9.

II. Hudson G, Carelli V, Spruijt L, Gerards M, Mowbray C, Achilli A, Pyle A, Elson J, Howell N, La Morgia C, Valentino ML, Huoponen K, Savontaus ML, Nikoskelainen E, Sadun AA, Salomao SR, Belfort R Jr., Griffiths P, Man PY, de Coo RF, Horvath R, Zeviani M, Smeets HJ, Torroni A, Chinnery PF: Clinical Expression of Leber Hereditary Optic Neuropathy Is Affected by the Mitochondrial DNA-Haplogroup Background. Am J Hum Genet 2007, 81 (2):228-233.

12. Bannwarth S, Procaccio V, Paquis-Flucklinger V: Surveyor Nuclease: a new strategy for a rapid identification of heteroplasmic mitochondrial DNA mutations in patients with respiratory chain defects. Hum Mutat 2005, 25(6):575-582.

13. Crespillo M, Paredes MR, Prieto L, Montesino M, Salas A, Albarrán C, Álvarez-Iglesias V, Amorin A, Berniell-Lee G, Brehm A, Carril JC, Corach D, Cuevas N, Di Lonardo AM, Doutremepuich C, Espinheira RM, Espinoza M, Gómez F, González A, Hernández A, Hidalgo M, Jimenez M, Leite FP, López AM, López-Soto M, Lorente JA, Pagano S, Palacio AM, Pestano JJ, Pinheiro MF, Raimondi E, Ramon MM, Tovar F, Vidal-Rioja L, Vide MC, Whittle MR, Yunis JJ, Garcia-Hirschfel J: Results of the 2003-2004 GEP-ISFG collaborative study on mitochondrial DNA: focus on the mtDNA profile of a mixed semen-saliva stain. Forensic Sci Int 2006, 160(2-3): 157-167.

14. Brandstätter A, Parsons TJ, Parson W: Rapid screening of mtDNA coding region SNPs for the identification of west European Caucasian haplogroups. Int J Legal Med 2003, I | 7(5):29|-298.

15. Bandelt HJ, Kivisild T, Parik J, Villems R, Bravi CM, Yao YG, Brandstätter A, Parson W: Lab-specific mutation processes. In Human mitochondrial DNA and the evolution of Homo sapiens Series: Nucleic Acids and Molecular Biology Volume I8. Edited by: H.-J. Bandelt MRVM. Berlin-Heidelberg, Springer-Verlag; 2006:I I $9-150$.

16. Quintáns B, Álvarez-Iglesias V, Salas A, Phillips C, Lareu MV, Carracedo : Typing of mitochondrial DNA coding region SNPs of forensic and anthropological interest using SNaPshot minisequencing. Forensic Sci Int 2004, I 40(2-3):25 I-257.

17. Álvarez-Iglesias V, Jaime JC, Carracedo, Salas A: Coding region mitochondrial DNA SNPs: targeting East Asian and Native American haplogroups. Forensic Sci Int: Genet 2007, I:44-55.

18. Brandstätter A, Salas A, Niederstätter H, Gassner C, Carracedo, Parson W: Dissection of mitochondrial superhaplogroup $\mathbf{H}$ using coding region SNPs. Electrophoresis 2007:254I-2550. 
19. Filippini S, Blanco A, Fernandez-Marmiesse A, Alvarez-Iglesias V, RuizPonte C, Carracedo A, Vega A: Multiplex SNaPshot for detection of BRCAI/2 common mutations in Spanish and Spanish related breast/ovarian cancer families. BMC Med Genet 2007, 8:40.

20. Salas A, Comas D, Lareu MV, Bertranpetit J, Carracedo : mtDNA analysis of the Galician population: a genetic edge of European variation. Eur J Hum Genet 1998, 6(4):365-375.

21. Salas A, Lareu MV, Sánchez-Diz P, Calafell F, Carracedo A: mtDNA hypervariable region II (HVII) sequences in human evolution studies: impact of mutation rate heterogeneity. Progress in Forensic Genetics 2000, 8:329-33I.

22. Achilli A, Rengo C, Magri C, Battaglia V, Olivieri A, Scozzari R, Cruciani F, Zeviani M, Briem E, Carelli V, Moral P, Dugoujon JM, Roostalu U, Loogvali EL, Kivisild T, Bandelt HJ, Richards M, Villems R, Santachiara-Benerecetti AS, Semino O, Torroni A: The molecular dissection of mtDNA haplogroup $H$ confirms that the FrancoCantabrian glacial refuge was a major source for the European gene pool. Am J Hum Genet 2004, 75(5):910-918.

23. Herrnstadt C, Elson JL, Fahy E, Preston G, Turnbull DM, Anderson C, Ghosh SS, Olefsky JM, Beal MF, Davis RE, Howell N: Reducedmedian-network analysis of complete mitochondrial DNA coding-region sequences from the major African, Asian, and European haplogroups. Am J Hum Genet 2002, 70: I I52-II7I.

24. Fernández-Marmiesse A, Salas A, Vega A, Fernández-Lorenzo JR, Barreiro J, Carracedo : Mutation spectra of ABCC8 gene in Spanish patients with Hyperinsulinism of Infancy (HI). Hum Mutat 2006, 27(2):214

25. Brage A, Tomé S, Garcia A, Carracedo, Salas A: Clinical and molecular characterization of Wilson disease in Spanish patients. Hepatol Res 2007, 37(I): 18-26.

26. Brown MD, Sun F, Wallace DC: Clustering of Caucasian Leber hereditary optic neuropathy patients containing the 11778 or 14484 mutations on an mtDNA lineage. Am J Hum Genet 1997, 60(2):38I-387.

27. Howell N, Oostra RJ, Bolhuis PA, Spruijt L, Clarke LA, Mackey DA, Preston G, Herrnstadt C: Sequence analysis of the mitochondrial genomes from Dutch pedigrees with Leber hereditary optic neuropathy. Am J Hum Genet 2003, 72(6): | 1460- | 469.

28. González AM, Brehm A, Pérez JA, Maca-Meyer N, Flores C, Cabrera VM: Mitochondrial DNA affinities at the Atlantic fringe of Europe. Am J Phys Anthropol 2003, I 20(4):39|-404.

29. Cassandrini D, Calevo MG, Tessa A, Manfredi G, Fattori F, Meschini MC, Carrozzo R, Tonoli E, Pedemonte M, Minetti C, Zara F, Santorelli FM, Bruno C: A new method for analysis of mitochondrial DNA point mutations and assess levels of heteroplasmy. Biochem Biophys Res Commun 2006, 342(2):387-393.

30. Álvarez-Iglesias V, Salas A, Cerezo M, Ramos-Luis E, Jaime JC, Lareu MV, Carracedo: Genotyping coding region mtDNA SNPs for Asian and Native American haplogroup assignation. Int Congress Series 2006, I I ( 288):4-6.

31. Bandelt HJ, Kong QP, Parson W, Salas A: More evidence for nonmaternal inheritance of mitochondrial DNA? J Med Genet 2005, 42:957-960.

32. Bandelt HJ, Salas A, Bravi CM: Problems in FBI mtDNA database. Science 2004, 305(5689): I 402-I 404.

33. Mitchell AL, Elson JL, Howell N, Taylor RW, Turnbull DM: Sequence variation in mitochondrial complex I genes: mutation or polymorphism? I Med Genet 2006, 43(2): I75-I79.

34. McFarland R, Taylor RW, Elson JL, Lightowlers RN, Turnbull DM, Howell N: Proving pathogenicity: when evolution is not enough. Am I Med Genet A 2004, I 3 I (I): 107-8; author reply I09-10.

35. DiMauro $S$, Schon EA: Mitochondrial DNA mutations in human disease. Am J Med Genet 200I, 106(I): 18-26.

36. Goto Y, Nonaka I, Horai S: A mutation in the tRNA(Leu)(UUR) gene associated with the MELAS subgroup of mitochondrial encephalomyopathies. Nature 1990, 348(6302):65I-653.

37. van den Ouweland JM, Lemkes HH, Ruitenbeek W, Sandkuijl LA, de Vijlder MF, Struyvenberg PA, van de Kamp J], Maassen JA: Mutation in mitochondrial tRNA(Leu)(UUR) gene in a large pedigree with maternally transmitted type II diabetes mellitus and deafness. Nat Genet 1992, I(5):368-37I.

38. Holt IJ, Harding AE, Petty RK, Morgan-Hughes JA: A new mitochondrial disease associated with mitochondrial DNA heteroplasmy. Am J Hum Genet 1990, 46(3):428-433.
39. de Vries DD, van Engelen BG, Gabreels FJ, Ruitenbeek W, van Oost $B A$ : A second missense mutation in the mitochondrial ATPase 6 gene in Leigh's syndrome. Ann Neurol 1993, 34(3):4I0-4I2.

40. Howell N, Bindoff LA, McCullough DA, Kubacka I, Poulton J, Mackey $D$, Taylor L, Turnbull DM: Leber hereditary optic neuropathy: identification of the same mitochondrial NDI mutation in six pedigrees. Am J Hum Genet I99I, 49(5):939-950.

4I. Johns DR, Neufeld MJ, Park RD: An ND-6 mitochondrial DNA mutation associated with Leber hereditary optic neuropathy. Biochem Biophys Res Commun 1992, 187(3): I55 I-I557.

42. Taylor RW, Turnbull DM: Mitochondrial DNA mutations in human disease. Nat Rev Genet 2005, 6(5):389-402.

43. Majamaa K, Moilanen JS, Uimonen S, Remes AM, Salmela PI, Karppa M, Majamaa-Voltti KA, Rusanen H, Sorri M, Peuhkurinen KJ, Hassinen IE: Epidemiology of A3243G, the mutation for mitochondrial encephalomyopathy, lactic acidosis, and strokelike episodes: prevalence of the mutation in an adult population. Am J Hum Genet 1998, 63(2):447-454.

44. Schaefer AM, Taylor RW, Turnbull DM, Chinnery PF: The epidemiology of mitochondrial disorders--past, present and future. Biochim Biophys Acta 2004, 1659(2-3): I I5- I 20.

45. Bandelt $\mathrm{HJ}$, Quintana-Murci L, Salas A, Macaulay V: The fingerprint of phantom mutations in mitochondrial DNA data. Am J Hum Genet 2002, 7 I(5): II50-II60.

46. Bandelt HJ, Salas A, Lutz-Bonengel S: Artificial recombination in forensic mtDNA population databases. Int J Legal Med 2004, I I 8(5):267-273.

47. Salas A, Bandelt HJ, Macaulay V, Richards MB: Phylogeographic investigations: The role of trees in forensic genetics. Forensic Sci Int 2007, 168: I- 13.

48. Salas A, Carracedo, Macaulay V, Richards M, Bandelt HJ: A practical guide to mitochondrial DNA error prevention in clinical, forensic, and population genetics. Biochem Biophys Res Commun 2005, 335(3):89|-899.

49. Salas A, Yao YG, Macaulay V, Vega A, Carracedo, Bandelt HJ: A critical reassessment of the role of mitochondria in tumorigenesis. PLoS Med 2005, 2(I I):e296.

50. Andrews RM, Kubacka I, Chinnery PF, Lightowlers RN, Turnbull DM, Howell N: Reanalysis and revision of the Cambridge reference sequence for human mitochondrial DNA. Nat Genet 1999, 23:147.

\section{Pre-publication history}

The pre-publication history for this paper can be accessed here:

http://www.biomedcentral.com/1471-2350/9/26/prepub

Publish with BioMed Central and every scientist can read your work free of charge

"BioMed Central will be the most significant development for disseminating the results of biomedical research in our lifetime. "

Sir Paul Nurse, Cancer Research UK

Your research papers will be:

- available free of charge to the entire biomedical community

- peer reviewed and published immediately upon acceptance

- cited in PubMed and archived on PubMed Central

- yours - you keep the copyright 